\title{
Comparison of I-131 Biokinetics after Recombinant Human TSH Stimulation and Thyroid Hormone Withdrawal Measured by External Detector in Patients with Differentiated Thyroid Cancer
}

\author{
Kalevi Kairemo ${ }^{1,3, *}$, Aki Kangasmäki ${ }^{2}$, and Hee-Seung Bom ${ }^{4, *}$ \\ ${ }^{1}$ Molecular Radiotherapy \& Nuclear Medicine, ${ }^{2}$ Finland Radiation Physics, Docrates Cancer Center, Helsinki, Finland, ${ }^{3}$ Department of \\ Nuclear Medicine, The University of Texas MD Anderson Cancer Center, Houston, TX, USA, ${ }^{4}$ Department of Nuclear Medicine, Chonnam \\ National University Medical School, Gwangju, Korea
}

The aim of this study was to compare radioactive iodine (I-131) biokinetics after recombinant human TSH stimulation (rhTSH) and thyroid hormone withdrawal (THW) in patients with differentiated thyroid cancer (DTC). External effective dose rates were measured using external detectors and imaged quantitatively at the time of discharge from the isolation wards. We retrospectively analyzed 32 patients who had been diagnosed with DTC, papillary or follicular, and underwent remnant ablation after either rhTSH stimulation $(n=22)$ or THW $(n=10)$. The uptake of I-131 by remnant thyroid tissue was measured from $20.0 \mathrm{~cm}, 100.0 \mathrm{~cm}$ and $200.0 \mathrm{~cm}$ distances using a handheld external detector. The remnant thyroid tissue measured by the whole body images two to five days from administration was $10.7+26.0 \%$ (range 0.5 to $60.0 \%$ ). The values measured at $20 \mathrm{~cm}$ were best correlated to the thyroid residual uptake measured by SPECT/CT. The half-lives of I-131washout (T1/2) in rhTSH group measured by external detector were shorter than those of THW group. T1/2 becomes longer when it was measured over longer distances. They were 10.9, 12.3 and 13.1 hours at distances of 20,100 , and $200 \mathrm{~cm}$ in rhTSH group, respectively. The TWH group showed 12.8, 14.9 and 17.7 hours, respectively. We conclude that I-131 biokinetics can be measured by external detector after high dose I-131 therapy for DTC. It showed that washout of I-131 was faster after rhTSH stimulation than THW, and slower in patients with distant metastasis than those without metastasis.

Key Words: Thyroid Neoplasms; Iodine Radioisotopes; Thyrotropin Alfa; Thyroidectomy; Neoplasm, Residual

This is an Open Access article distributed under the terms of the Creative Commons Attribution Non-Commercial License (http://creativecommons.org/licenses/by-nc/4.0) which permits unrestricted non-commercial use, distribution, and reproduction in any medium, provided the original work is properly cited.

\section{Article History:}

Received October 12, 2018

Revised December 25, 2018

Accepted December 26, 2018

\author{
Corresponding Author: \\ Kalevi Kairemo \\ Molecular Radiotherapy \& Nuclear \\ Medicine, Docrates Cancer Center, \\ Saukonpaadenranta 2, FI-00180, \\ Helsinki, Finland \\ Tel: $+358-10-7732000$ \\ Fax: +358-10-773 2099 \\ E-mail: kalevi,kairemo@docrates.com

\section{Hee-Seung Bom} \\ Department of Nuclear Medicine, \\ Chonnam National University Medical \\ School, 160 Baekseo-ro, Dong-gu, \\ Gwangju 61469, Korea \\ Tel: $+82-61-379-7270$ \\ Fax: $+82-61-379-7281$ \\ E-mail: henryhsbom@gmail.com
}

\section{INTRODUCTION}

Ablation of remnant thyroid tissue by administration of radioactive iodine (I-131) after total thyroidectomy is a safe and effective treatment in patients with differentiated thyroid cancer (DTC), which provides a better prognosis and reliable follow-ups for DTC patients by measuring serum thyroglobulin (Tg). ${ }^{1-6}$ Successful ablation is usually defined as no visible uptake in the thyroid bed in diagnostic scan or, if visible, a percentage uptake $<0.1 \%, 6-8$ months after radioiodine therapy, and/or a stimulated serum $\mathrm{Tg}$ concentration $<1 \mathrm{ng} / \mathrm{mL}$. ${ }^{7}$ Thyroid remnant may be defined as normal thyroid tissue or microscopic disease in the thyroid bed left by the surgeon after total or near-total thyroidectomy.

Recombinant human TSH (rhTSH) is a convenient and safe tool to stimulate I-131 uptake by the remnant thyroid tissue. ${ }^{8,9}$ The preliminary results using rhTSH for remnant ablation (RA) were very encouraging. It was as effective as thyroid hormone withdrawal (THW) for RA, while the remnant absorbed dose was higher, while the whole-body dose was lower.

Biokinetics of I-131 can be reliably analyzed by measuring radioactivities of blood by well counter as well as of 
whole body by serial quantitative gamma camera imaging. Radiation exposure to staff at the time of imaging and blood sampling is a major concern especially when they are done immediately after I-131 administration. Radioactivity of DTC patients after I-131 administration is routinely measured by hand-held external detector at the bedside until the patients are safely discharged from the isolation ward. The purpose of this study was to evaluate whether the I-131 biokinetics can be analyzed by external detector measurements of radioactivity in DTC patients. We compared the results of rhTSH and THW groups, based on the distances of measurement.

\section{MATERIALS AND METHODS}

We retrospectively analyzed 32 patients who had been diagnosed with DTC, papillary or follicular, and underwent RA treatment after either rhTSH stimulation $(n=22)$ or THW ( $n=10$ ) from May 2013 to June 2015. The characteristics of patients are summarized in Table 1 . There were no differences between two groups including in hemodynamic parameters. The patients followed-up for three years. This retrospective analysis was performed according to the principles of the Declaration of Helsinki. The database of this study was approved by the Finnish authority for the protection of privacy and personal data.

The rhTSH (Thyrogen ${ }^{\circledR}$; Genzyme Corp., Boston, MA, USA) stimulation was performed 1 and 2 days before oral administration of I-131. THW was done for at least 4 weeks. Administered I-131 doses varied from 1054 to $6801 \mathrm{MBq}$. Nine patients had primarily metastatic disease at the time of ablation. Lower doses (1054 to $3684 \mathrm{MBq}$ ) were used for patients without metastases, and higher doses (5043 to $6801 \mathrm{MBq}$ ) were used for patients with metastases.

We measured the effective dose rate outside the body with handheld external survey meters (Rados RDS-120, Rados, Turku, Finland) at a daily $20 \mathrm{~cm}$ distance from the jugulum, and 100 and $200 \mathrm{~cm}$ distances from the xiphoid process, which were measured by a laser distance meter (Bosch PLR 15, Robert Bosch, Stuttgart, Germany) until

TABLE 1. Characteristics of patients

\begin{tabular}{lccl}
\hline & rhTSH group & THW group & \\
\hline $\mathrm{N}$ & 22 & 10 & \\
Age (mean \pm SD, years) & $54.0 \pm 14.4$ & $43.5 \pm 16.7$ & $\mathrm{p}=0.107$ \\
Sex (male:female) & $7: 15$ & $3: 7$ & \\
Stage I & 4 & 1 & \\
Stage II & 7 & 6 & \\
Stage III & 5 & 1 & \\
Stage IV & 6 & 2 & \\
Administered activity of & $3900 \pm 1630$ & $4370 \pm 863$ & $\mathrm{p}=0.296$ \\
I-131 (mean \pm SD, MBq) & & & \\
Pathology & $17: 5$ & $8: 2$ & \\
(Papillary:Follicular) & & & \\
\hline
\end{tabular}

rhTSH: recombinant human thyroid stimulating hormone, THW: thyroid hormone withdrawal, SD: standard deviation. release from the isolation room (Fig. 1). The release criteria was $15 \mu \mathrm{Sv} / \mathrm{h}$ from 1 meter based on the requirements of the Finnish Nuclear Safety Authority, STUK. The experimental design of the measurements is shown in Fig. 1. Although RDS-120 is not compliant with $\mathrm{H}^{*}(10)$ dose equivalent measurement as per ICRU/ICRP recommendations, our half-life determinations do not require $\mathrm{H}^{*}(10)$ measurement. The background dose rate was about 0.1 $\mathrm{mSv} / \mathrm{h}$, which is so low that it was not subtracted from the measurements. The $20 \mathrm{~cm}$ distance measurement was not corrected for high count rate losses, because the effect was estimated to be similar or less than the uncertainties of the distance during measurement for a quenched GeigerMüller tube. The count rate effect was considered negligible at $100 \mathrm{~cm}$ or $200 \mathrm{~cm}$. Single exponent fits in Excel (Microsoft Corp., Redmont, WA, USA) were used to obtain total radionuclide half-lives. Whole body gamma camera imaging followed by SPECT/CT of neck and thorax was acquired using Siemens Symbia gamma camera two to five days after the administration of I-131calculated quantitatively the residual disease using geometric mean.

Patients were grouped according to TSH stimulation (rhTSH vs. THW) and distant metastasis (absent vs. present). The statistical difference was analyzed using a paired t-test and multivariate analysis. The two-tailed test was used in all cases. A p value below 0.05 was considered statistically significant.

\section{RESULTS}

The remnant thyroid tissue measured by the whole body images two to five days from administration was $10.7 \pm$ $26.0 \%$ (range 0.5 to $60.0 \%$ ). The values measured at $20 \mathrm{~cm}$ were best correlated to the thyroid residual uptake measured by SPECT/CT. R square values were $0.63,0.36$, and 0.24 at distances 20,100 and $200 \mathrm{~cm}$.

The half-lives of I-131washout (T1/2) in rhTSH group were shorter than those of THW group. T1/2 becomes longer when it was measured longer distances. They were $10.9,12.3$ and 13.1 hours at distances of 20,100 , and 200

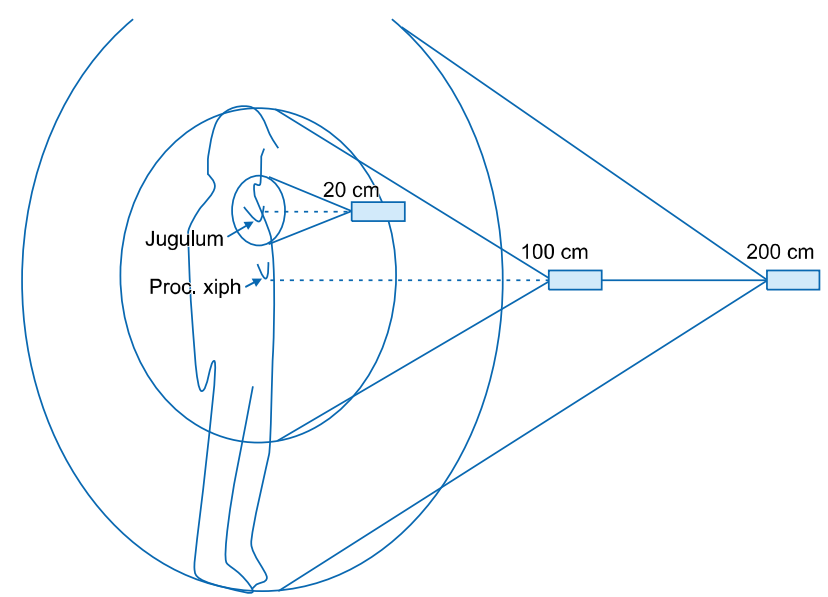

Fig. 1. Experimental design of detector measurements. 
A

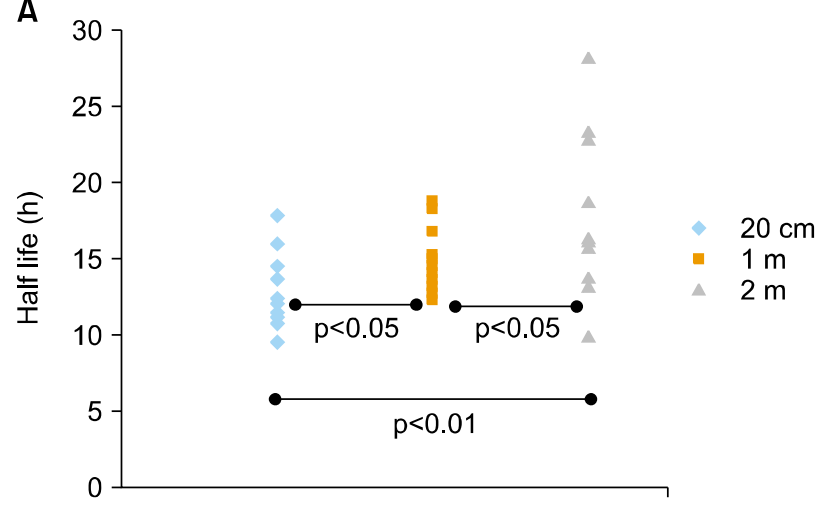

B

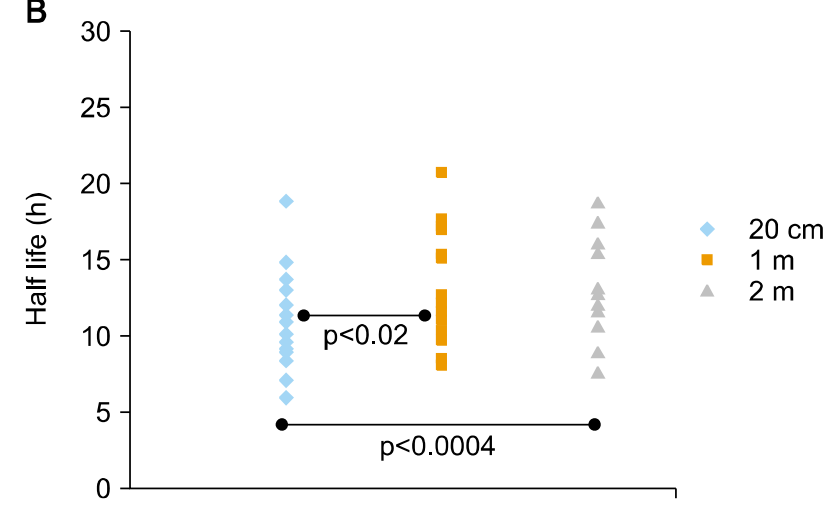

FIG. 2. Half-lives based on the distance of the measurement, THW (A) and rhTSH (B).

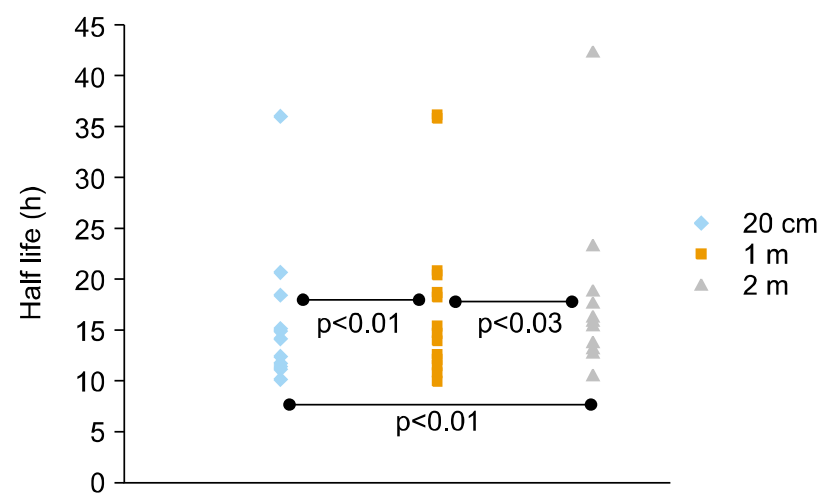

FIG. 3. Half-lives based on the distance of the measurement in patients who were primarily metastatic.

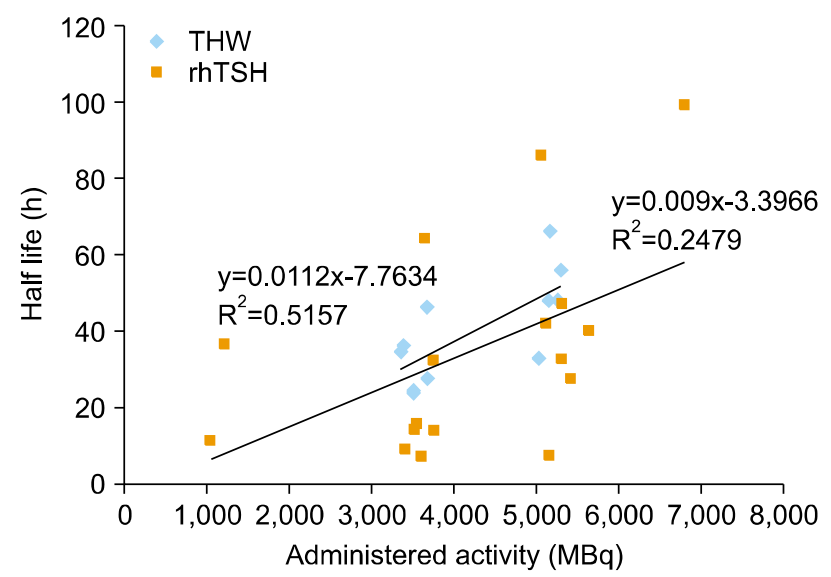

FiG. 4. Half-lives vs. administered activity in THW and rhTSH groups.

cm in rhTSH group, respectively. TWH group showed 12.8, 14.9 and 17.7 hours, respectively. The differences between $20 \mathrm{~cm}, 100 \mathrm{~cm}$ and $200 \mathrm{~cm}$ measurements distances $(20$ $\mathrm{cm}-2 \mathrm{~m}, 20 \mathrm{~cm}-1 \mathrm{~m}, 1 \mathrm{~m}-2 \mathrm{~m}$ ) were all statistically significant from each other within THW (Fig. $2 \mathrm{~A}$ ) group ( $\mathrm{p}=0.01$, 0.007 and 0.01 ) and $20-100 \mathrm{~cm}$ and $20-200 \mathrm{~cm}$ in rhTSH group ( $\mathrm{p}=0.02$ and 0.0004), the data is shown in Fig. 2B.

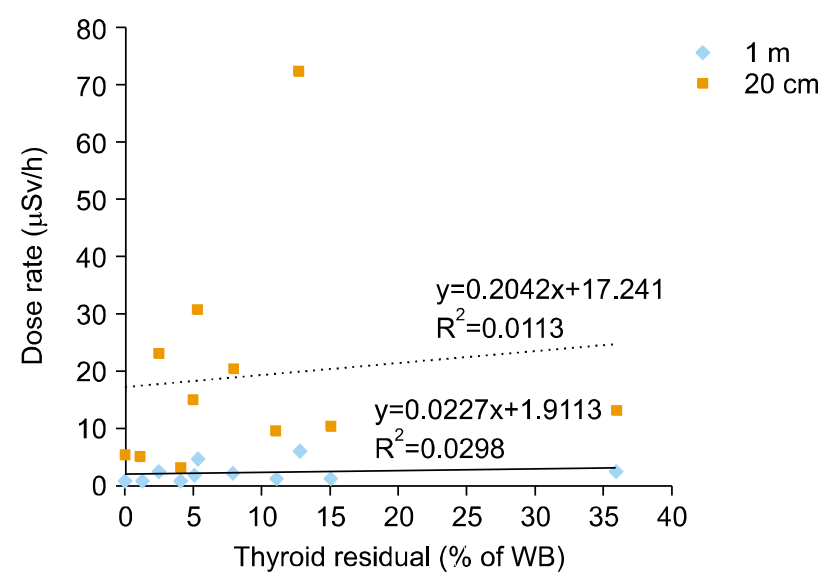

FiG. 5. Size of thyroid residue vs. dose rate from $20 \mathrm{~cm}$ and 100 $\mathrm{cm}$ distances (at the time of whole body gamma imaging).

When patients had metastases, these between $20 \mathrm{~cm}, 100 \mathrm{~cm}$ and $200 \mathrm{~cm}$ were statistically significant (Fig. 3), p values are $0.01,0.01$ and $0.03(20 \mathrm{~cm}-2 \mathrm{~m}, 20 \mathrm{~cm}-1 \mathrm{~m}, 1 \mathrm{~m}-2 \mathrm{~m})$. The administered dose of I-131 was not related to the halflives.

When patients did not have metastases, these between $20 \mathrm{~cm}, 100 \mathrm{~cm}$ and $200 \mathrm{~cm}$ were not statistically significant (Fig. 3), p values are 0.05, 0.09 and $0.46(20 \mathrm{~cm}-2 \mathrm{~m}, 20 \mathrm{~cm}-$ $1 \mathrm{~m}, 1 \mathrm{~m}-2 \mathrm{~m})$.

The kinetic parameters between the THW and rhTSH group did not differ from each other on average (Fig. 4). However, in the rhTSH group at activity levels 3-5.5 GBq there was one patient who had higher activity than others. Fig. 4 shows a trend that the half-life was shorter when treatment is combined with rhTSH.

The dose rate, if measured from $20.0 \mathrm{~cm}$ or $100.0 \mathrm{~cm}$ distance, does not correlate with thyroid residue activity (Fig. 5). $\mathrm{T} 1 / 2$ was longer in patients with distant metastasis than those without metastasis. T1/2 in metastasis group were $13.9,15.5$ and 17.9 hours in 20,100 , and $200 \mathrm{~cm}$, respectively. They were 11.0, 13.1 and 14.5 hours, respectively in the non-metastasis group. A case with successful RA therapy is shown in Fig. 6. 
A

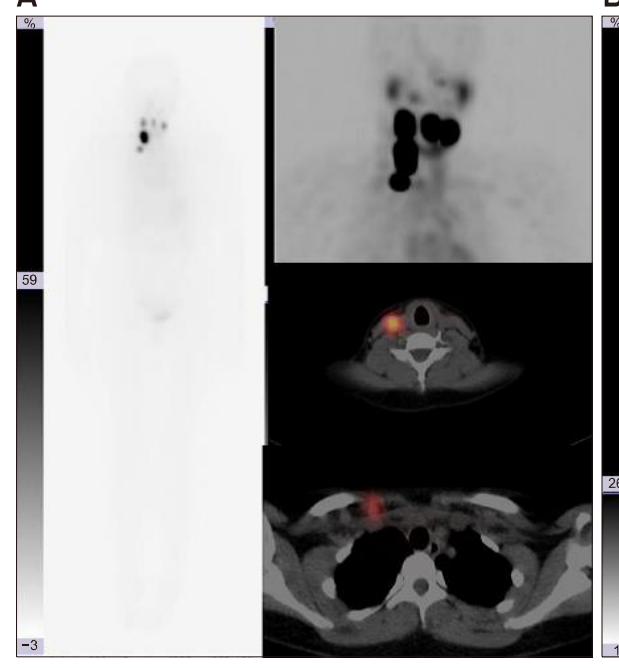

I-131-Tx
B

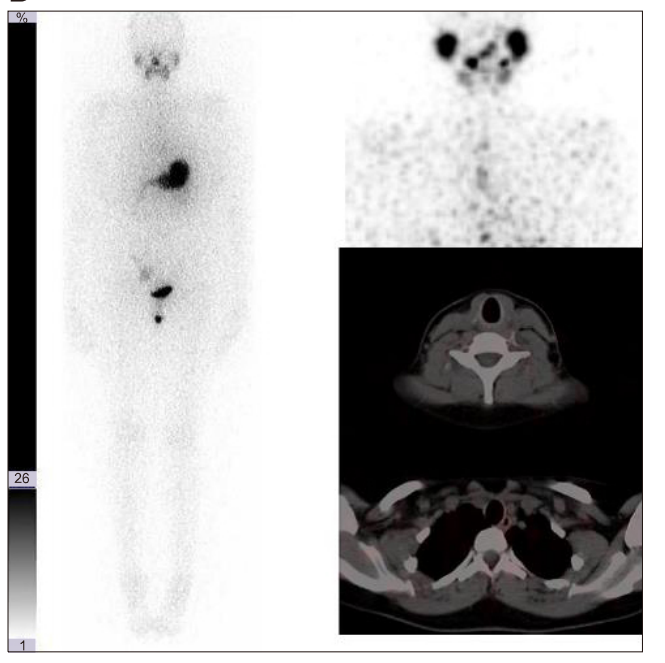

|-123-Dx6 mo later
FiG. 6. (A) Imaging with I-131-therapy dose. Patient with thyroid residue and locoreginal neck metastases on the right in the neck region at 46 hours after receiving $5177 \mathrm{MBq}$ with rhTSH stimulation. The effective half-lives were $17.8 \mathrm{~h}$ $(20 \mathrm{~cm}), 18.4 \mathrm{~h}(100 \mathrm{~cm})$ and $23.4(200 \mathrm{~cm})$. (B) Imaging with I-123-imaging dose. All the lesions in the thyroid bed and neck region disappeared 6 months later, as shown by imaging at 24 hours after iv-injection $200 \mathrm{MBq}$ of I-123.

\section{DISCUSSION}

In this retrospective study of 32 patients at various clinical stages we found that I-131 biokinetics could be measured by a handheld external detector after a high dose I-131 therapy for DTC. The amount of the remnant thyroid tissue could be also assumed using the external detector. The values measured by external detector at $200 \mathrm{~cm}$ were best correlated to those measured by quantitative SPECT/CT, which ranged from 0.5 to $60 \%$ indicating a very heterogeneous patient population. The heterogeneity of the patient population is very understandable because the patients came from different institutions not only in Finland but from neighboring countries.

The feasibility of using a handheld external detector to analyze I-131 biokinetics has a practical meaning. It needs at least three values to analyze the biokinetics. Radioactivity from the residual thyroid tissue can be accurately measured by quantitative SPECT/CT imaging. Acquisition of whole-body imaging early after the high dose I-131 administration is practically impossible because of high radiation exposure to the hospital staff. Daily measurement of radioactivity at 1 meter from the patient until the release from the isolation room is the current, routine clinical practice. This practice is mandatory to make sure that the radiation from the patient is lower than the release criteria, which is $15 \mu \mathrm{Sv} / \mathrm{h}$ from 1 meter distance in Finland.

One critical problem of biokinetic analysis by external detector is that the origin of the radioactivity cannot be clearly indicated. It is also not clear what distance is the best to analyze the I-131 biokinetics using an external detector. There were significant differences of T1/2 according to distances of measurement. Radioactivity measured at $20 \mathrm{~cm}$ from the jugulum mainly reflects radiation from the residual thyroid tissue as well as cervical lymph nodes. Radioactivity measured at 1 and 2 meters from the xiphoid process contains radiation from the whole body. It is rea- sonable that the values measured at shorter distances correlated to better to the uptake measured by SPECT/CT as they reflect the cervical thyroid remnant activities. It is also reasonable that I-131 washout is faster in rhTSH group as compared to the THW group as expected from the literature..$^{10,11}$

It is noteworthy that there was no difference of $\mathrm{T} 1 / 2$ at $20 \mathrm{~cm}$ in both rhTSH and THW groups. The half-life of 20 $\mathrm{cm}$ uptake was lower than the $1 \mathrm{~m}$ uptake in both THW and rhTSH groups. The difference seems to be bigger in THW group. I-131 biokinetics in remnant thyroid tissue is not well understood. ${ }^{11-14}$ It has been postulated that I-131 discharge from thyroid cancer cells could be faster than from normal thyroid cells. ${ }^{11,12}$ However, the $20 \mathrm{~cm}$ distance is not good enough to separate activity from salivary glands, thyroid remnants, nor neck metastases from each other. Fig. 6 shows multiple radiation sources for external detectors from $20 \mathrm{~cm}$ distance, i.e. thyroid remnants, multiple neck metastases, and salivary glands. Additional disturbing factors, such as contaminations, may occur in the neck area and its effect has been described in the literature. ${ }^{15}$

North American studies ${ }^{16-18}$ showed that RA use was associated with a significantly decreased risk of locoregional recurrence and distant metastases which could be confirmed in later meta-analyses. ${ }^{19}$ This indicates that RA is an important daily practice and evidence-based medicine which can be applicable to special patient groups. ${ }^{20,21}$ Although there are concerns of radiation safety and radiation-induced secondary hematologic malignancies, ${ }^{22}$ many investigators emphasize the greater benefits as compared to the radiation risks. ${ }^{23,24}$

There are several limitations in this preliminary study. First of all, the patient group was heterogeneous because we collected data retrospectively from daily practice. Secondly, the sample size was small as the data come from one institute. That said, this practice is common in many nuclear medicine services in many countries in the world. This study can be meaningful if it can be applied to daily 
practice of RA therapy for DTC.

From this study we conclude that I-131 biokinetics can be measured by external detector after high dose I-131 therapy for DTC. It showed that washout of I-131 was faster after rhTSH stimulation than THW, and slower in patients with distant metastasis than those without metastasis. The gamma imaging has additional information to the external detector in terms of the location of residual thyroid tissue and metastasis.

\section{ACKNOWLEDGEMENTS}

The authors are thankful to Wonjun Jung, MD, from the Department of Orthopaedics, Chonnam National University Hospital Gwangju, Korea for helping in the data collection.

\section{CONFLICT OF INTEREST STATEMENT}

None declared.

\section{REFERENCES}

1. Beierwaltes WH, Rabbani R, Dmuchowski C, Lloyd RV, Eyre P, Mallette S. An analysis of "ablation of thyroid remnants" with I-131 in 511 patients from 1947-1984: experience at University of Michigan. J Nucl Med 1984;25:1287-93.

2. McCowen KD, Adler RA, Ghaed N, Verdon T, Hofeldt FD. Low dose radioiodide thyroid ablation in postsurgical patients with thyroid cancer. Am J Med 1976;61:52-8.

3. Kayano D, Taki J, Inaki A, Wakabayashi H, Nakamura A, Fukuoka M, et al. Thyroid hormone replacement one day before (131)I therapy in patients with well-differentiated thyroid cancer. Asia Ocean J Nucl Med Biol 2013;1:20-6.

4. Bal CS, Padhy AK. Radioiodine remnant ablation: a critical review. World J Nucl Med 2015;14:144-55.

5. Jabin Z, Kwon SY, Bom HS, Lin Y, Yang K, Inaki A, et al. Clinico-social factors to choose radioactive iodine dose in differentiated thyroid cancer patients: an Asian survey. Nucl Med Commun 2018;39:283-9.

6. Wakabayashi H, Taki J, Inaki A, Toratani A, Kayano D, Kinuya S. Extremity radioactive iodine uptake on post-therapeutic whole body scan in patients with differentiated thyroid cancer. Asia Ocean J Nucl Med Biol 2015;3:26-34.

7. Duntas LH, Cooper DS. Review on the occasion of a decade of recombinant human TSH: prospects and novel uses. Thyroid 2008;18:509-16.

8. Robbins RJ, Tuttle RM, Sonenberg M, Shaha A, Sharaf R, Robbins $\mathrm{H}$, et al. Radioiodine ablation of thyroid remnants after preparation with recombinant human thyrotropin. Thyroid 2001;11:865-9.

9. Berg G, Lindstedt G, Suurküla M, Jansson S. Radioiodine ablation and therapy in differentiated thyroid cancer under stimulation with recombinant human thyroid-stimulating hormone. J Endocrinol Invest 2002;25:44-52.

10. Hänscheid H, Lassmann M, Luster M, Thomas SR, Pacini F, Ceccarelli $\mathrm{C}$, et al. Iodine biokinetics and dosimetry in radioiodine therapy of thyroid cancer: procedures and results of a prospective international controlled study of ablation after rhTSH or hor- mone withdrawal. J Nucl Med 2006;47:648-54.

11. Hong CM, Kim CY, Son SH, Jung JH, Lee CH, Jeong JH, et al. I-131 biokinetics of remnant normal thyroid tissue and residual thyroid cancer in patients with differentiated thyroid cancer: comparison between recombinant human TSH administration and thyroid hormone withdrawal. Ann Nucl Med 2017;31:582-9.

12. Schlumberger M, Lacroix L, Russo D, Filetti S, Bidart JM. Defects in iodide metabolism in thyroid cancer and implications for the follow-up and treatment of patients. Nat Clin Pract Endocrinol Metab 2007;3:260-9.

13. Taïeb D, Sebag F, Farman-Ara B, Portal T, Baumstarck-Barrau $\mathrm{K}$, Fortanier $\mathrm{C}$, et al. Iodine biokinetics and radioiodine exposure after recombinant human thyrotropin-assisted remnant ablation in comparison with thyroid hormone withdrawal. J Clin Endocrinol Metab 2010;95:3283-90.

14. Hung BT, Huang SH, Huang YE, Wang PW. Appropriate time for post-therapeutic I-131 whole body scan. Clin Nucl Med 2009;34: 339-42.

15. Kairemo K. Thyroid doses and skin contaminations of radioiodine. J Nucl Med Radiat Ther 2015;6:244.

16. Mazzaferri EL, Jhiang SM. Long-term impact of initial surgical and medical therapy on papillary and follicular thyroid cancer. Am J Med 1994;97:418-28.

17. Samaan NA, Maheshwari YK, Nader S, Hill CS Jr, Schultz PN, Haynie TP, et al. Impact of therapy for differentiated carcinoma of the thyroid: an analysis of 706 cases. J Clin Endocrinol Metab 1983;56:1131-8.

18. Simpson WJ, Panzarella T, Carruthers JS, Gospodarowicz MK, Sutcliffe SB. Papillary and follicular thyroid cancer: impact of treatment in 1578 patients. Int J Radiat Oncol Biol Phys 1988;14: 1063-75.

19. Sawka AM, Thephamongkhol K, Brouwers M, Thabane L, Browman G, Gerstein HC. Clinical review 170: a systematic review and metaanalysis of the effectiveness of radioactive iodine remnant ablation for well-differentiated thyroid cancer. J Clin Endocrinol Metab 2004;89:3668-76.

20. Byun BH, Kwon SY, Chong A, Kim J, Yoo SW, Min JJ, et al. Both F-18 FDG-avidity and malignant shape of cervical lymph nodes on PET/CT after total thyroidectomy predict resistance to high-dose I-131 therapy in patients with papillary thyroid cancer. Asia Ocean J Nucl Med Biol 2013;1:6-13.

21. Chereau N, Trésallet C, Noullet S, Godiris-Petit G, Tissier F, Leenhardt L, et al. Prognosis of papillary thyroid carcinoma in elderly patients after thyroid resection: a retrospective cohort analysis. Medicine (Baltimore) 2016;95:e5450.

22. Molenaar RJ, Sidana S, Radivoyevitch T, Advani AS, Gerds AT, Carraway HE, et al. Risk of hematologic malignancies after radioiodine treatment of well-differentiated thyroid cancer. J Clin Oncol 2018;36:1831-9.

23. Tulchinsky M, Baum RP, Bennet KG, Freeman LM, Jong I, Kairemo K, et al. Well-founded recommendations for radioactive iodine treatment of differentiated thyroid cancer require balanced study of benefits and harms. J Clin Oncol 2018;36:1887-8.

24. Tulchinsky M, Binse I, Campennì A, Dizdarevic S, Giovanella L, Jong I, et al. Radioactive iodine therapy for differentiated thyroid cancer: lessons from confronting controversial literature on risks for secondary malignancy. J Nucl Med 2018;59:723-5. 